\title{
Educação física escolar, co-educação e gênero: mapeando representações de discentes
}

Mauro Louzada de Jesus* Fabiano Pries Devide**

\begin{abstract}
Resumo: A pesquisa teve como objetivo investigar as representações dos alunos(as) sobre as aulas de Educação Física escolar(EFe) separadas por sexo e mistas. Utilizou uma entrevista com um grupo focal composto de seis alunos do ensino médio, três homens e três mulheres, e um teste de associação livre de palavras. A análise e interpretação dos dados indicam que: i) os alunos não são capazes de analisar e interpretar as aulas de EFe separadas por sexo e mistas numa perspectiva Co-Educativa; e ii) os professores(as) não têm problematizado questões de gênero durantes suas aulas.

Palavras-chave: Educação Física e treinamento. Escolar.

Identidade de gênero. Educação primária e secundária.
\end{abstract}

\section{INTRODUÇÃO}

O debate sobre Educação Física escolar (EFe) na interface com a Co-Educação no Brasil se inicia na década de 1990. As questões de gênero emergem na formação profissional, buscandose alternativas pedagógicas para as aulas de Educação Física (EF) que viabilizassem mudanças nas relações de poder entre os sexos na prática dos desportos e das atividades físicas durante as aulas, desconstruindo binarismos sobre os corpos masculino e feminino, suas possibilidades de ação e suas potencialidades (ABREU, 1992, 1995; SOUZA E ALTMANN, 1999; ALTMANN, 2002). Neste contexto, a EFe contribuiu para masculinizar o deporto e feminizar

\footnotetext{
* Mestrando em Educação Física e Cultura (PPGEF-UGF/RJ). Professor da SEE/RJ e da SME/Teresópolis.

E-mail: mauro.tere@uol.com.br

* Doutor em Educação Física e Cultura (PPGEF-UGF/RJ), Professor Adjunto do PPGCAFUniverso/RJ. Professor Adjunto do Centro Universitário Augusto Motta/UNISUAM/RJ. Coord.Grupo de Pesquisa Gênero na Educação Física e Esportes/UNISUAM/RJ. Profes-
} sor da SEE/RJ. E-mail : fabianodevide@uol.com.br

Movimento, Porto Alegre, v.12, n. 03, p. 123-140, setembro/dezembro de 2006. 
as atividades rítmico-expressivas, socializando corpos masculinos e femininos, porém, separando-os (SARAIVA, 2002).

Nesta pesquisa temos como situação problema responder à questão: Quais os elementos presentes nas representações dos discentes sobre as aulas de EFe Separadas por sexo e Mistas? Para interpretação dos dados, apresentamos sucintamente metodologias de ensino utilizadas na distribuição dos discentes por sexo na EFe; abordamos o conceito de gênero; alguns estudos sobre o uso de aulas Mistas, Separadas por sexo e Co-educativas na EFe; por fim, apresentamos a construção da pesquisa, seguida da análise e interpretação dos dados.

\section{GÊNERO E EDUCAÇÃO FÍSICA ESCOLAR}

Intelectuais da EF têm utilizado as idéias de Joan Scott para analisar e interpretar as questões de gênero na EFe no Brasil (ABREU, 1992, 1995; SARAIVA, 1999; SOUSA, ALTMANN, 1999; ALTMANN, 2002; LUZ JÚNIOR, 2003; MOURÃO, 2003; ROMERO, 2004; GOELLNER, 2005). Para fins deste trabalho, nos orientamos pela definição do Dicionário Crítico de Educação Física, que a partir do diálogo com alguns intelectuais, interpreta Gênero como uma "[...] construção social do sexo. Ou seja, como categoria analítica e política, evidencia que masculino e feminino são construções sociais e históricas" (GOELLNER, 2005, p.207).

As questões de gênero permeiam diversas instâncias sociais, inclusive o contexto escolar (MEYER; SOARES, 2004). Louro (2001) focaliza como a aula de EFe torna-se um contexto de elaboração das identidades de gênero, construindo masculinidades e feminilidades a partir da participação em atividades corporais: "Se em algumas áreas escolares a constituição da identidade de gênero parece, muitas vezes, ser feita através dos discursos implícitos, nas aulas de EF esse processo é, geralmente mais explícito e evidente."(p.72).

Na EF brasileira os estudos sobre as questões de "gênero" 
sofreram influências, respectivamente, norte-americana (gender studies) e francesa (estudos feministas); desenvolvendo-se a partir da década de 1980 (GOELLNER, 2001; LUZ JÚNIOR, 2003). A partir da produção acadêmica, consolidaram-se algumas linhas de pesquisa em alguns programas de pós-graduação em EF, tais como os da Universidade Federal do Rio Grande do Sul (UFRGS) e Universidade Gama Filho (UGF).

Entretanto, a produção acadêmica, sobretudo as dissertações de mestrado e teses de doutorado defendidas entre as décadas de 1980 e 1990, além de focalizarem o estudo de estereótipos e papéis sexuais com foco no locus escolar como possibilidade reduzida de abordar relações de gênero; apresentam confusões conceituais como o gênero identificado enquanto sinônimo de sexo; a confusão conceitual entre identidade sexual e identidade de gênero; e a dificuldade na distinção entre estudos de "gênero" e estudos sobre "mulheres" (LUZ JÚNIOR, 2003). Tais pesquisas debruçaram-se, por exemplo, sobre aspectos relacionados aos conteúdos generificados e generificadores na Efe, a distribuição dos discentes por sexos nas aulas ou os padrões de inclusão e exclusão por gênero na $\mathrm{EFe}$.

A emergência da temática de gênero na EF foi relevante para se tomar ciência dos mecanismos de inclusão e exclusão atravessados pelas questões de gênero, auxiliando a sua intervenção. Saraiva $(2002$, p. 83) afirma que a EF deve refletir sobre a "[...] importância do papel dos (as) professores (as) na problematização e vivência das questões de gênero, na prática pedagógica, junto aos seus alunos/as. E, para isso, eles(as) próprios (as) precisam estar esclarecidos". Todavia, Meyer (2004, p. 11) alerta que não é tarefa fácil para o docente perceber as diferenças entre o que é natural e o que é cultural: "A compreensão de que gênero e sexualidade são culturalmente construídos e não 'naturalmente' dados não é imediata".

O contexto torna-se desafiador e gera a necessidade do deba-

Movimento, Porto Alegre, v.12, n. 03, p. 123-140, setembro/dezembro de 2006. 
te sobre a temática para que o docente da EFe possa desvelar a naturalização das desigualdades de gênero, reconhecendo a pluralidade inerente às fronteiras entre o masculino e o feminino, desafiando e transgredindo a norma natural expressa e imposta socialmente pela equação: sexo-gênero-heterossexualidade (BUTLER, 2003; LOURO, 2004), e suas relações com as práticas sociais desenvolvidas na experiência de participação nas práticas corporais da EF.

Nesta pesquisa, focalizamos as representações dos discentes sobre a separação de meninos e meninas nas aulas, por identificarmos a existência de uma incidência de aulas separadas por sexo nas escolas públicas em que já atuamos. No entanto, por que as aulas de EFe são separadas por sexo, enquanto nas outras disciplinas não são? Como ministrar simultaneamente uma aula para alunos e alunas separadamente? Há espaço para se trabalhar questões de gênero neste contexto?

Se os corpos de alunos e alunas estão juntos nas salas de aula, também poderiam compartilhar juntos o espaço da EFe. Nas aulas de EFe nas quais o docente esteja preocupado com a educação integral de seus alunos, não se justifica a separação dos sexos, impedindo alunos e alunas de se desenvolverem e aprenderem a conviverem juntos, respeitando-se mutuamente. Se a aula de EFe não é uma sessão de treinamento esportivo, a separação dos sexos não pode ser pautada sobre as bases biológicas, tais como diferenças de habilidade motora ou força entre alunos e alunas (SARAIVA, 1999). Questões sociais, culturais e históricas também influenciam as práticas de separação e devem ser consideradas pelos docentes.

3 AULAS DE EDUCAÇÃO FÍSICA COM SEPARAÇÃO DOS SEXOS

Durante as aulas separadas, o docente tende a não dar a atenção necessária aos dois grupos simultaneamente, prejudicando o

Movimento, Porto Alegre, v.12, n. 03, p. 123-140, setembro/dezembro de 2006. 
andamento e a qualidade da aula. Em escolas que não possuem ambiente físico adequado, alunos e alunas ficam aguardando para alternarem o uso do espaço, enquanto se a EFe fosse organizada de forma Mista ou Co-educativa, ambos poderiam participar ativamente durante todo o período da aula.

O argumento comum apresentado para separação dos sexos na EFe é a alegação da falta de habilidade motora das alunas, o que prejudicaria o desenvolvimento da aula.Isto tem raízes culturais identificadas por Abreu (1992), quando a autora observou que irmãos e irmãs tendem a receber uma educação diferenciada, com os meninos dispondo de mais tempo livre para brincadeiras, enquanto as meninas são mais solicitadas pelas mães para ajudarem nos afazeres domésticos, tendo menos tempo livre para brincar e vivenciando experiências motoras mais tarde, nas aulas de EFe. Ao longo da História, as mulheres recebem um tratamento desigual em relação às oportunidades na vida social, gerando um desequilíbrio no desenvolvimento social de homens e mulheres: os primeiros educados para a vida pública enquanto elas são educadas para a vida privada. Meyer (2004, p. 9) comentando estas desigualdades afirma:

A força corporal foi, por muito tempo, um importante argumento, dentre outros, para explicar a superioridade dos homens sobre as mulheres. Características anatômicas como o tamanho e formato da bacia explicaram e justificaram a maternidade como destino natural da mulher.

Quando propomos a separação de alunos e alunas para alguma atividade na $\mathrm{EFe}$, os meninos tendem a dominar o espaço físico da quadra. Scraton (1992)1 apud Louro (2001) afirma que desde a

1 SCRATON, S. Educación Física de lãs ninas: um enfoque feminista. Madrid: Morata, 1992.

Movimento, Porto Alegre, v.12, n. 03, p. 123-140, setembro/dezembro de 2006. 
infância, meninas aprendem não apenas a proteger os seus corpos, mas também a ocuparem um "espaço corporal pessoal muito limitado", desenvolvendo uma "timidez corporal". A atitude dos alunos reproduz as relações de gênero atravessadas pela categoria do poder sobre o domínio espacial. A intervenção do docente sensível às questões de gênero poderá problematizar este desequilíbrio no domínio do espaço com os discentes, questionando possibilidade de igualdade com relação ao uso do espaço da quadra de desportos.

\section{AULA DE EDUCAÇÃO FÍSICA MISTA}

As aulas mistas surgiram no panorama da EFe argumentando a possibilidade de desconstrução de estereótipos sexuais e a viabilização dos conteúdos para ambos os sexos, de forma igualitária. Não é tarefa simples para os docentes desenvolverem aulas Mistas de forma harmônica, quando os alunos (as) estão acostumados com aulas separadas. Abreu (1992, p. 115) constatou que: "Num primeiro momento há um bloqueio por parte dos meninos em aceitar praticar atividades junto com as meninas. Assim que estas meninas demonstram habilidade em executar determinada tarefa, este incômodo desaparece".

Por este fator, no início do ano letivo, quando alunos e alunas são estimulados a participarem de aulas Mistas, identificamos o sentimento de recusa por parte de ambos os grupos. A problematização da construção cultural das diferenças de gênero em relação à participação de homens e mulheres em determinadas modalidades de desporto, a partir de discussões construídas na interação das aulas, tende a diminuir os conflitos de gênero entre os sexos. A intervenção pedagógica do docente torna-se fundamental para a desconstrução de alguns estereótipos e a minimização da separação dos sexos nas aulas de EFe, incentivando a prática de alunos e alunas nas mesmas atividades corporais, contribuindo para o desenvolvimento da solidariedade, gerando um melhor entendimento da construção social das diferenças de gênero e conse-

Movimento, Porto Alegre, v.12, n. 03, p. 123-140, setembro/dezembro de 2006. 
qüentemente, a tolerância de ambos os sexos, sobre o seu desempenho nas atividades motoras propostas.

Outro aspecto é o fato de alguns docentes considerarem que suas aulas são organizadas de forma "Mista". Na realidade, estes docentes tendem a receber a turma com alunos e alunas e dividirem o tempo de uso do espaço físico, reservando uma parte da aula aos alunos e outra às alunas; ou simultaneamente, de um lado da quadra os alunos e do outro lado alunas, fazendo atividades separadas, contribuindo para a reprodução da naturalização das diferenças de gênero entre os sexos, conforme apontado por outros autores (SOUSA; ALTMANN, 1999, ALTMANN, 2002, SARAIVA, 1999, 2002).

\section{AULAS DE EDUCAÇÃO FÍSICA CO-EDUCATIVAS}

As aulas co-educativas são uma prática na qual os alunos e alunas tendem a estarem juntos participando das atividades propostas na aula, quando podem ser problematizadas as questões de gênero inerentes às atividades. Sobre a Co-educação, Saraiva (1999, p. 181) ressalta:

Torna-se importante trazer para o campo da discussões e possibilidades pedagógicas as questões [...] como: os papéis sexuais estereotipados, os anseios irracionais de dominação dos homens, a opressão tradicional da mulher $e$, principalmente a ameaça ao direito de melhores condições e igualdade dos seres humanos no esporte e na educação física.

$\mathrm{Na} \mathrm{EF}$ as práticas corporais vivenciadas por alunos(as) geram representações diferenciadas para homens e mulheres, constroem preconceitos e estereótipos relacionados a quem pode ou deve praticá-las, contribuindo para que o movimento corporal esteja impregnado por padrões de conduta, impedindo a co-educação (SARAIVA, 2002). Quando tais questões não são problematizadas pelo docente junto aos discentes, turmas de $\mathrm{EFe}$

Movimento, Porto Alegre, v.12, n. 03, p. 123-140, setembro/dezembro de 2006. 
que nunca vivenciaram uma abordagem Co-educativa, tendem a oferecer dificuldades para a realização das atividades.

Entre os motivos para as aulas serem Co-educativas, Brodtmann (1986) apresenta dois argumentos básicos, a saber: i) ampliar vivências esportivas e as capacidades motoras de ambos os sexos para práticas de lazer; ii) contribuir para a estabilização de grupos heterogêneos quanto ao sexo, visando melhorar sua interação social.

A co-educação como abordagem metodológica para a EFe contribui para interpretar o desporto e as atividades físicas numa perspectiva relacional de gênero, combatendo o sexismo, libertando alunos e alunas das amarras que determinam o que cada sexo pode vivenciar como práticas corporais. $\mathrm{Na}$ dança, por exemplo, os arranjos de gênero custam mais aos homens do que às mulheres, por possibilitarem que estes manifestem a expressividade emocional/movimentos, aspectos que transgridem o que se associa ao masculino pela sociedade; enquanto o contrário ocorre com o futebol no caso das mulheres (SARAIVA, 2002).

Esta tendência binária entre o masculino e o feminino, passa a ser desconstruída a partir de uma abordagem Co-educativa que problematiza as descontinuidades nas representações do feminino e masculino presentes nos novos espaços ocupados por homens (espaço privado, cuidado dos filhos/as) e mulheres (espaço público, trabalho profissional) na sociedade (LOURO, 2004).

\section{METODOLOGIA}

A pesquisa de caráter qualitativo e descritivo (THOMAS; NELSON, 2002), teve como situação problema responder: Quais são as representações dos discentes sobre as aulas de EFe Separadas por sexo e Mistas? Justifica-se pela recorrência de aulas de EFe separadas por sexo - não oportunizando a problematização das questões de gênero -, apesar do crescimento da produção acadêmica sobre co-educação na EF.

Movimento, Porto Alegre, v.12, n. 03, p. 123-140, setembro/dezembro de 2006. 
O objetivo central foi identificar as representações dos alunos (as) sobre as aulas de EFe Separadas por sexo e Mistas. Para coleta de dados, utilizamos uma entrevista de grupo focal (GASKELL, 2002) e um teste de associação livre de palavras com seis alunos, três do sexo masculino e três do sexo feminino matriculados no segundo ano do ensino médio de uma escola estadual do Rio de Janeiro, com idade entre quatorze e dezesseis anos.

De acordo com Gaskell (2002), para seleção dos integrantes de um grupo focal, "as diferenças de status entre os participantes não são levadas em consideração" (p. 79). Para fins do estudo, consideramos os informantes do grupo focal como "sujeitos genéricos", no sentido conferido por Spink (1995), pois tendem a representar o grupo em si, via discurso. Sendo assim, utilizamos como critério central para selecionar os discentes participantes do grupo focal todos terem necessariamente vivenciado aulas de Educação Física com turmas mistas e com turmas separadas por sexo em anos anteriores.

Para a análise e a interpretação dos dados, foram utilizadas a análise de conteúdo (BARDIN, 1995) e a análise do discurso (ORLANDI, 1996, 2002), que via linguagem, buscam identificar os sentidos emergentes em construção no discurso.

\section{RESULTADOS}

Para desencadear a discussão sobre as possíveis representações dos discentes sobre as aulas de EFe Separadas por sexo e Mistas, apresentamos alguns recortes das falas reunidas a partir da entrevista de grupo focal. Após a análise e interpretação do discurso construído pelo grupo, identificamos uma marca discursiva comum: a preferência das aulas de EFe Separadas por sexo. A partir da análise de conteúdo (BARDIN, 1995), construímos duas categorias: as aulas Separadas por sexo e as aulas Mistas.

Movimento, Porto Alegre, v.12, n. 03, p. 123-140, setembro/dezembro de 2006. 


\subsection{Educação Física escolar Separada por sexo}

Identifica-se que há uma preocupação dos alunos e alunas com a possibilidade de homogeneidade em termos de habilidade motora e aptidão física. Segundo o grupo, isto possibilita "liberdade", além de "jogar de igual para igual". Renan afirma: "É melhor porque um pode aumentar o nível do outro, pode ser um jogo com um nível mais alto. (...) A liberdade do jogo é maior separado"; enquanto Michelly diz que "O nível é mais ou menos o mesmo e tem como jogar de igual pra igual [...]" [grifo nosso].

Liberdade, no discurso de Renan relaciona-se a poder jogar com todo o seu potencial físico, o que pressupõe utilizar a força, a agilidade, a velocidade e a habilidade para jogar o desporto, possibilidade abreviada quando a aula é Mista e os alunos precisam se adequar às possibilidades de jogo das alunas, uma vez que fazem parte da mesma equipe.

As alunas tendem a focalizar o discurso na violência dos alunos, traduzida pela "brutalidade", que representa ameaça de lesão física. A presença de alunos no jogo misto tende a intimidar as alunas, que optam por tornarem-se coadjuvantes, sem terem iniciativa em participar: "Quando as meninas estão sozinhas, elas têm uma coragem maior de tentar jogar" (Michelly); ou como ressalta Mayara: "Eu prefiro as aulas separadas, porque os garotos são muito brutos" [grifo nosso]. O mesmo quadro foi encontrado por Andrade (2005), sobre as representações sociais de alunas do ensino médio sobre a sua auto-exclusão nas aulas de Educação Física, quando identificou a brutalidade dos alunos em relação às alunas como um dos elementos constituintes das representações sociais das alunas que contribuíam para a sua auto-exclusão das aulas.

A construção das diferenças de aptidão física e habilidades motoras não foram questionadas pelo grupo focal, aspectos já identificados como sendo determinantes na exclusão por gênero nas aulas de EFe (ALTMANN, 2002). Identifica-se que o grupo interpreta estas diferenças de habilidades motoras como naturais, re-

Movimento, Porto Alegre, v.12, n. 03, p. 123-140, setembro/dezembro de 2006. 
sultantes das diferenças biológicas e não das influências sócioculturais e históricas relacionadas às práticas corporais e comportamentos destinados aos sexos na sociedade, desconsiderando-se as questões de gênero, conforme aponta Saraiva (1999).

Apenas um aluno enunciou um aspecto negativo das aulas Separadas por sexo: “(...) homem e mulher separados, eu acho que um ficaria com um nível muito acima do outro" (Eduardo). O aluno critica a aula separada por sexo, porque as alunas não teriam oportunidades de elevar o seu nível de aptidão física e habilidade motora, aspecto que só poderia ser conquistado na presença dos alunos nas aulas. O discurso demonstra, contudo, como os alunos não vislumbram a possibilidade de aprenderem com as alunas, que tendem a serem interpretadas sempre como inferiores do ponto de vista motor. Gomes, Silva e Queirós (2004, p. 176) vão ressaltar que este quadro se perpetua enquanto a "Educação Física tende a favorecer a reprodução e consolidação de estereótipos quando opta por currículos muito centrados nos jogos desportivos conotados com o masculino".

\subsection{Educação Física escolar mista}

Os pontos positivos apontados pelos alunos em jogarem com as alunas na aula Mista referem-se ao prazer de jogarem juntos, assim como a possibilidade de elevarem o nível de habilidade motora das alunas, que podem aprender mais com eles. Eduardo afirma que a aula de EFe mista "[...] foi uma idéia legal, porque transformou o ambiente da Educação Física num ambiente mais agradável", enquanto Felipe diz que "[...] a gente pode aumentar o nível das meninas, com certeza" [grifo nosso], consolidando o discurso dos alunos sobre a incompetência motora das alunas para lhes ensinarem algo sobre o desporto e a atividade física.

A desvantagem que o grupo justificou para as aulas Separadas por sexo, relacionada à heterogeneidade dos sexos quanto à habilidade motora, surge com nova roupagem o que demonstra a construção do discurso no grupo focal em direção a EFe Mista como sendo uma possibilidade de intervenção mais igualitária em relação ao gênero.

Movimento, Porto Alegre, v.12, n. 03, p. 123-140, setembro/dezembro de 2006. 
A brutalidade, palavra mais recorrente no discurso do grupo focal, é notada pelos alunos e alunas, tendo como conseqüência o desejo delas em não jogarem com eles nas aulas mistas, devido ao medo de se machucarem. Renan e Michelly explicitam suas opiniões sobre este aspecto, quando afirmam, respectivamente: "Eu não acho legal porque pode ter uma certa brutalidade em relação dos meninos com as meninas" e "[...] os garotos acham que eles estão jogando com outros garotos e ficam na brutalidade [...] acham que a gente é do mesmo nível deles". [grifo nosso]. O espaço do jogo transforma-se numa arena reservada para a expressão da virilidade e construção da masculinidade, privilegiando as vantagens biológicas dos meninos, excluindo-as do jogo (DUNNING; MAGUIRE, 1997, LOURO, 2001, GOMES; SILVA; QUEIRÓS, 2004).

\subsection{Análise da Associação de Palavras}

Após aplicação de um teste de Associação Livre de Palavras, a análise dos dados desencadeou a construção de sete categorias-chave associadas às aulas de EFe Separadas por sexo e Mistas, conforme as tabelas a seguir:

Tabela 1: Associação livre de palavras para EFe separada por sexo.

\begin{tabular}{|c|c|c|c|c|}
\hline \multicolumn{5}{|c|}{ EFe SEPARADA POR SEXO } \\
\hline Categoria & Subcategoria & $\mathrm{N}$ & $\%$ & Palavras \\
\hline Violência & & 2 & 4,5 & Sem dor (1), Briga (1). \\
\hline \multirow[t]{2}{*}{ Socialização } & Positiva & 9 & $\begin{array}{c}19 \\
5\end{array}$ & $\begin{array}{l}\text { Ativa (1), Participativa (7), Menos } \\
\text { individualidade (1). }\end{array}$ \\
\hline & Negativa & 2 & 4,5 & Individualismo (1), Menor participação (1). \\
\hline Intensidade & & 6 & 13 & $\begin{array}{l}\text { Rendimento (3), Competitiva (2), } \\
\text { Treinamento (1) }\end{array}$ \\
\hline \multirow[t]{2}{*}{$\begin{array}{c}\text { Organização da } \\
\text { Aula }\end{array}$} & Positiva & 7 & 15 & $\begin{array}{l}\text { Aprendizado (1), Organizada (2), } \\
\text { Homogênea (2), Dinamismo (1), Disciplina } \\
\text { (1). }\end{array}$ \\
\hline & Negativa & 5 & 11 & $\begin{array}{l}\text { Confusão (2), Menor tempo (1), Gritaria (1), } \\
\text { Bagunça (1). }\end{array}$ \\
\hline Prazer & & 9 & $\begin{array}{c}19, \\
5\end{array}$ & $\begin{array}{l}\text { Muito boa (5), Divertida (2), Interessante } \\
\text { (1), Melhor (1). }\end{array}$ \\
\hline Monotonia & & 4 & 8,5 & $\begin{array}{l}\text { Sem graça (1), Chata (1), Caída (1), } \\
\text { Desânimo (1). }\end{array}$ \\
\hline $\begin{array}{c}\text { Grau de } \\
\text { Dificuldade }\end{array}$ & & 2 & 4,5 & Difícil (2). \\
\hline Total & & 46 & 100 & \\
\hline
\end{tabular}

Movimento, Porto Alegre, v.12, n. 03, p. 123-140, setembro/dezembro de 2006. 
Entre as categorias centrais, os discentes destacaram, respectivamente: a socialização positiva, o sentimento de prazer, a organização positiva da aula e a alta intensidade nas atividades realizadas. Os dados sugerem indícios das representações dos discentes para aulas de EFe Separadas por sexo, cujos elementos podem ser assim enumerados: i) aulas com baixo índice de violência entre alunos/as; ii) socialização positiva possibilitando maior participação de ambos os sexos nas atividades específicas apresentadas pelo docente; iii) homogeneidade em termos de aptidão física e habilidades motoras, permitindo maior intensidade nas atividades; e iv) organização positiva gerando satisfação e prazer nos discentes.

Neste contexto, para fins deste estudo, conclui-se que tanto os alunos quanto as alunas tendem a preferir as aulas de EFe Separadas por sexo, ao destacarem a maior participação e liberdade nas atividades, com menos violência.

Tabela 2: Associação livre de palavras para EFe mista.

\begin{tabular}{|c|c|c|c|l}
\hline \multicolumn{5}{|c}{} \\
\hline Categoria & Subcategoria & $\mathrm{N}$ & $\%$ & \multicolumn{1}{|c}{ Palavras } \\
\hline Violência & & $\mathbf{8}$ & $\mathbf{1 7}$ & $\begin{array}{l}\text { Violenta (3), Com dor (2), Receio do uso da } \\
\text { força (1), Injusta (2). }\end{array}$ \\
\hline Socialização & Positiva & $\mathbf{3}$ & $\mathbf{6 , 5}$ & Cooperação (1), Participativa (2) \\
\cline { 2 - 6 } & Negativa & $\mathbf{6}$ & $\mathbf{1 3}$ & $\begin{array}{l}\text { Panelinha (1), Menos participativa (3), Falta de } \\
\text { companheirismo (1), Individualidade (1). }\end{array}$ \\
\hline Intensidade & & $\mathbf{6}$ & $\mathbf{1 3}$ & $\begin{array}{l}\text { Mais rendimento (3), Esforço (1), Rivalidade (1), } \\
\text { Menos rendimento (1). }\end{array}$ \\
\hline $\begin{array}{c}\text { Organizaçã } \\
\text { o da Aula }\end{array}$ & Positiva & $\mathbf{0}$ & $\mathbf{0}$ & (Nenhuma ocorrência) \\
\cline { 2 - 6 } & negativa & $\mathbf{9}$ & $\mathbf{1 9}$ & $\begin{array}{l}\text { Enrolada (2), Indisciplina (1), Cheia (1), Confusa } \\
\text { (5). }\end{array}$ \\
\hline Prazer & & $\mathbf{9}$ & $\mathbf{1 9}$ & $\begin{array}{l}\text { Interessante (2), Legal (2), Ótima (1), Divertida } \\
\text { (3), Animação (1). }\end{array}$ \\
\hline Monotonia & & 2 & 4 & Lenta (1), Chata (1). \\
\hline $\begin{array}{c}\text { Grau de } \\
\text { Dificuldade }\end{array}$ & & 4 & $\mathbf{8 , 5}$ & Dificuldade (3), Mais fácil (1). \\
\hline Total & & 47 & 100 & \\
\hline & & & &
\end{tabular}

Entre as categorias centrais, os discentes destacaram, respectivamente: a organização negativa das aulas, o prazer, a violência, a socialização negativa e a alta intensidade nas atividades. Os

Movimento, Porto Alegre, v.12, n. 03, p. 123-140, setembro/dezembro de 2006. 
dados sugerem alguns elementos das representações dos discentes sobre as aulas de EFe Mistas, a saber: i) aulas com alto índice de violência entre alunos e alunas; ii) apresentam socialização negativa, ressaltando-se os aspectos como a brutalidade e o individualismo sexista; iii) heterogeneidade do ponto de vista da aptidão física e das habilidades motoras; iv) organização negativa da aula (não foi associada nenhuma palavra è organização positiva); v) sentimento de prazer.

Sendo assim, para fins deste estudo, conclui-se que tanto os alunos quanto as alunas explicitam desvantagens nas aulas de EFe Mistas, ao destacarem as categorias supracitadas.

A partir das características mencionadas, identifica-se uma ausência de postura co-educativa por parte de docentes em aulas de EFe Mistas, impedindo o desenvolvimento, por parte dos discentes, de valores como cooperação, socialização, participação e respeito entre os sexos, o que sugere um desconhecimento dos docentes em relação à co-educação e ao conceito de gênero, enquanto referenciais que possam auxiliá-los nos conflitos comuns entre alunos e alunas durante as aulas de EFe.

\section{CONSIDERAÇÕES FINAIS}

As representações das aulas de EFe Separadas por sexo se constroem a partir dos seguintes elementos: i) maior homogeneidade; ii) menor violência; iii) ênfase no rendimento motor; iv) maior participação dos alunos(as) com uma socialização positiva; v) mais organização das atividades propostas. As representações sobre as aulas de EFe Mistas se constroem a partir dos elementos: i) maior heterogeneidade; ii) violência; iii) socialização negativa, devido ao individualismo e aos grupos organizados com base na divisão dos sexos; iv) menor organização das atividades propostas. A marca discursiva comum para ambas as aulas foi o prazer, denotando ser uma categoria que atravessa as aulas de EFe.

Buscando estabelecer relações entre os dados da entrevista 
focal e da associação livre de palavras, encontramos como marcas comuns na entrevista focal e na evocação livre de palavras para aulas de EF Separadas por sexo: participação (socialização positiva) e o rendimento motor (intensidade); enquanto as marcas comuns na entrevista focal e na associação livre de palavras para aulas de EF Mistas foram: a violência e a menor participação (socialização negativa).

Nas aulas de EFe Separadas por sexo, Mistas e também coeducativas, o docente se depara com conflitos. No discurso dos discentes, encontramos indícios de que durante as aulas de EFe, a temática de gênero e a proposta co-educativa não vêm sendo desenvolvidas pelos docentes, contribuindo para que a cooperação, o respeito às diferenças, a participação efetiva dos alunos, a socialização, entre outros valores, fiquem à margem das práticas de alunos e alunas durante as aulas, não contribuindo para que o convívio entre os sexos seja mais humano.

O estudo demonstrou uma tendência nos discentes representarem positivamente as aulas de EFe Separadas por sexo e negativamente as aulas de EFe Mistas. Para a construção de uma EFe igualitária entre os sexos, os docentes devem distribuir os alunos(as) nas aulas de EFe implementando uma proposta Co-Educativa, que problematize questões de gênero e contribuam para a melhoria da convivência entre os sexos com/através/na prática corporal, facilitando a socialização, o combate ao sexismo, a diminuição da violência e a melhoria da sua organização.

Movimento, Porto Alegre, v.12, n. 03, p. 123-140, setembro/dezembro de 2006. 
School physical education, co-education, and gender: a look into students social representations

Abstract: This exploratory study aims to investigate the representations of high school students about those physical education classes that separate sexes or those that happens with boys and girls together. It used a focal group interview with six students, composed by three men and three women, and a test of free association of words. The analysis suggest that: i) students don't analyse or interpret the physical education classes that separate sexes or that happens with boys and girls together, into a co-educative perspective; and ii) the teachers don't discuss gender questions during their classes.

Keywords: Physical Education and training. Education, primary and secondary. Gender identity.

Educación física escolar, co-educación e genero: mapeando las representaciones discentes Resúmen: Lo estudio tiñe como objetivo investigar las representaciones de los estudiantes sobre las aulas de Educación Física escolar (Efe) separadas por sexo e mixtas. Fue realizada una entrevista de grupo focal con seis estudiantes de lo grado medio de enseñanza, tres hombres e tres mujeres, e un teste de evocación libre de palabras. Los dados indican que: i) los alumnos no son capaces de analizar e interpretar las aulas de EFe separadas por sexo e mixtas en una perspectiva Co-Educativa; e ii) los profesores(as) non tienen trabajado quesotes de genero durante las aulas. Palabras clave: Educación e entrenamiento físico. Educación primaria y secundaria. Identidad de género. 


\section{REFERÊNCIAS}

ABREU, N. G. Análise das percepções de docentes e discentes sobre turmas mistas e separadas por sexo nas aulas de Educação Física Escolar. In: ROMERO E. (org.). Corpo, Mulher e Sociedade. São Paulo: Papirus, 1995. p. 157-176.

ABREU, N.G.. Meninos pra cá, meninas pra lá? In: VOTRE, S. J. (org.). Ensino e avaliação em educação física. São Paulo: Ibrasa, 1992. p.101-120.

ALTMANN, H. Exclusão nos esportes sob um enfoque de gênero. Motus Corporis. Rio de Janeiro, v. 9, n. 1, p. 9-20, 2002.

ANDRADE, E. B. As representações Sociais de alunas sobre sua auto-exclusão nas aulas de Educação Física no Ensino Médio. In: ENCONTRO FLUMINENSE DE EDUCAÇÃO FÍSICA ESCOLAR, 9. 2005. Anais... Niterói: DEFD-UFF, 2005. p. 102-105.

BARDIN, L. Análise de conteúdo. Lisboa: Edições 70, 1995.

BRODTMANN, D. Aprendizagem social na Educação Física. In: DIECKERT, J.; KURZ, D.; BRODTMANN, D. Elementos e princípios da Educação Física: uma antologia. Rio de Janeiro: Livro Técnico, 1986. p. 93-122.

BUTLER, J. Problemas de Gênero: feminismo e subversão da identidade. Rio de Janeiro: Civilização Brasileira, 2003.

DUNNING, E.; MAGUIRE, J. As relações entre os sexos no esporte. Estudos Feministas, Rio de Janeiro, v. 5, n. 2, p. 312-348, 1997

GASKELL, G. Entrevistas individuais e grupais. In: BAUER, M.W.; GASKELL, G. (Eds.). Pesquisa qualitativa com texto, imagem e som. Petrópolis,RJ: Vozes, 2002.

GOELLNER, S. V. Gênero, Educação Física e Esportes. In.: Votre, S. (org.) Imaginário e Representações Sociais em Educação Física, Esporte e Lazer 2001. p. 215-227.

GOELLNER, S. V. Gênero. In: GONZÁLEZ, J. M.; FENSTERSEIFER, P. E. (org) Dicionário crítico de Educação Física. ljuí: Unijuí, 2005. p. 207-209.

GOMES, P. B.; SILVA, P.; QUEIRÓS, P. Por uma estrutura pedagógica renovada promotora da co-educação no desporto. In.: SIMÕES, Antonio C.; KNIJNIK, Jorge D. (org.) O Mundo Psicossocial da Mulher no Esporte: comportamento, gênero, desempenho. São Paulo: Aleph, 2004. p. 173-189.

LOURO, G. L. Gênero, Sexualidade e Educação: uma perspectiva pósestruturalista. Petrópolis, RJ: Vozes, 2001.

LOURO, G. L. Um corpo estranho: ensaios sobre sexualidade e teoria queer. Belo Horizonte: Autêntica, 2004

Movimento, Porto Alegre, v.12, n. 03, p. 123-140, setembro/dezembro de 2006. 
LUZ JÚNIOR, A. A. Educação Física e Gênero: olhares em cena. São Luis: Imprensa Universitária UFMA/CORSUP, 2003.

MEYER, D. E.; SOARES, R. de F. R. Corpo, gênero e sexualidade nas práticas escolares: um início de reflexão. In.: MEYER, D. E.; SOARES, R. de F. R. (org.). Corpo, gênero e sexualidade. Porto Alegre: Mediação, 2004. p. 5-16.

MOURÃO, L. Exclusão e inserção da mulher brasileira em atividades físicas e esportivas. In.: SIMÕES, A. C. (org.). Mulher e Esporte: mitos e verdades, 2003. p. $123-154$.

ORLANDI, E. P. As formas do silêncio: no movimento dos sentidos. Campinas, SP: Editora da Unicamp, 2002.

ORLANDI, E. P. Discurso e Leitura. Campinas, SP: Cortez, Editora da Unicamp, 1996.

ROMERO, E. A (In) Visibilidade da Mulher Atleta no Jornalismo Esportivo do Rio de Janeiro. In.: SIMÕES, A. C.; KNIJNIK, J. D. (org.). O Mundo Psicossocial da Mulher no Esporte: comportamento, gênero, desempenho. São Paulo: Aleph. 2004, p. 213-252.

SARAIVA, M. do C. Co-educação Física e Esportes: quando a diferença é mito. ljuí: Unijuí, 1999.

SARAIVA, M. do C. Por que investigar as questões de gênero no âmbito da Educação Física, Esporte e Lazer? Motrivivência, v.13, n. 19, p. 79-85, 2002.

SOUSA, E. S. de; ALTMANN, H. Meninos e meninas: expectativas corporais e implicações na Educação Física Escolar. Cadernos Cedes, Campinas,SP, v. 19, n. 48, p. 52-68, 1999.

SPINK, M. J. Desvelando as teorias implícitas: uma metodologia de análise das representações sociais. In: GUARESCHI, P.; JOVTCHELOVITCH, S. (org.). (1995).

Textos em representações sociais. 2. ed. Petrópolis, RJ: Vozes, 1995. p.117145.

THOMAS, J. R.; NELSON, J. K. Métodos de Pesquisa em Atividade Física. São Paulo: Artmed, 2002. 